\title{
Hepatitis B in Ghana: a systematic review \& meta-analysis of prevalence studies $(1995-2015)$
}

\author{
Richard Ofori-Asenso ${ }^{*}$ and Akosua Adom Agyeman
}

\begin{abstract}
Background: Although, chronic hepatitis B (HBV) is considered to be of significant public health importance in Ghana, not many reviews detailing the burden (prevalence) of the disease have been conducted. This study was aimed at summarizing the available information and to make an accurate estimate of HBV infection prevalence in Ghana over the last two decades (1995-2015).
\end{abstract}

Methods: A systematic search was conducted in PubMed, ScienceDirect, Google Scholar and Africa Journals Online (AJOL) databases to retrieve primary studies published between $1^{\text {st }}$ January 1995 and $4^{\text {th }}$ October 2015, assessing the prevalence of HBV among populations in Ghana. This was supplemented by a manual search of retrieved references.

Results: Thirty (30) studies across all the ten (10) regions of Ghana and involving an overall population size of 105,435 were analyzed. The national prevalence of HBV as determined by HBsAg seropositivity was $12.3 \%$. HBV prevalence among voluntary blood donors (VBDs), replacement blood donors (RBDs) and pregnant women were $10.8,12.7$ and $13.1 \%$ respectively. HBV infection prevalence was highest among studies published within the period 1995-2002 (17.3 \%), followed by those published within 2003-2009 (14.7\%) and the lowest prevalence rate being recorded across studies published in the period 2010-2015 (10.2\%). Regional prevalence were determined for Ashanti, Greater Accra, Eastern, Northern, central and Brong-Ahafo regions as 13.1, 10.6, 13.6, 13.1, 11.5 and $13.7 \%$ respectively. No aggregate data were derived for Volta, Western, Upper East and Upper West regions. Higher prevalence of HBV infection was attained for rural (13.3 \%) compared to urban settings (12.2\%). Across the country, highest HBV infection prevalence rates were recorded in persons within the age group 16-39 years.

Conclusion: Hepatitis B infection is clearly an important public health problem in Ghana. The burden of the disease as dictated by a high prevalence rate calls for urgent public health interventions and strategic policy directions to controlling the disease to avert any potential future explosion.

Keywords: Hepatitis B, Viral infections, Endemicity, Ghana, Meta-analysis

\section{Background}

Viral Hepatitis A, B, C, D and E cause significant morbidity and mortality affecting more people worldwide than even HIV [1]. Nearly 2 billion people across the world are estimated to be infected with Hepatitis B Virus (HBV) with nearly a quarter of this having chronic infection $[2,3]$. Each year, over half a million HBV-related deaths are recorded across the globe [4].

\footnotetext{
* Correspondence: asensox215@gmail.com
}

Research Unit, Health Policy Consult, P. O. Box WJ 537, Weija-Accra, Ghana
Epidemiological studies have often demonstrated varying levels of endemicity of HBV worldwide, with highly endemic areas present in Sub-Saharan Africa (SSA) and East Asia, where between 5 and $10 \%$ of the adult population are deemed to be chronically infected [5]. In Western Europe and North America, Less than $1 \%$ of the population is chronically infected. The lifetime risk of infection from HBV in many African and Asian countries, the Amazon Basin and parts of the Middle East is estimated to be more than $60 \%$ [6]. Accurate determination of the burden of HBV in Africa is difficult owing 
to poor record keeping and under-reporting, but estimates put that about $70-95 \%$ of the adult population show evidence of past exposure to HBV infection and the HBsAg seroprevalence rate has been put around 6-20\% [6, 7].

Chronic HBV increases individuals' risk of progressive liver disease and hepatocellular carcinoma (HCC). In the natural history of HBV infection, it is estimated that 10 to $33 \%$ of those who develop persistent infection would end up with chronic hepatitis of which 20 to $50 \%$ may develop liver cirrhosis [8]. HCC is a highly aggressive cancer with limited treatment options, often lacking in many resource-poor settings such as Africa [9]. SSA has one of the highest HBV-related liver cancer rates in the world [10]. HBV-related liver cancer also remains the most common cancer among males and the third most common cancer among females in the African region $[11,12]$. Of significant importance is that, the average age of HCC development in Africa is considerably younger than in other more advanced regions (mean age 33 years compared to 60 years in Western Europe) meaning HBV-related HCC affects patients in their most productive and reproductive years [9]. HBV therefore represents a critical threat to health as well as other developmental and economic parameters on the African continent.

In Ghana, HBV is considered to be of significant public health importance and a disease that requires greater attention [13, 14]. Ghana has been grouped as part of the areas of the world where the prevalence of chronic HBV infection is high $(\geq 8 \%)[9,15]$. Sweitzer et al. for instance in estimating the global burden of hepatitis B in 2013, put the prevalence of chronic hepatitis B virus infection in Ghana at $12.92 \%$ [3]. However, this was derived from an analysis of only 12 studies. Some experts have also put the prevalence rate of $\mathrm{HBV}$ in Ghana to be around $10-15 \%[16,17]$. A scoping of the literature identified no other thoroughly conducted reviews specifically summarizing data on prevalence of HBV in Ghana. This observation points out that although there may have been significant research into understanding the burden of HBV in Ghana, the evidence available remains fragmented. To overcome this perceived gap in evidence compilation, we conducted a systematic review to thoroughly summarize the available information towards answering the key question; what has been the prevalence of HBV in Ghana over the last two decades (1995-2015)?

\section{Methods}

\section{Study area}

Ghana is located along the Gulf of Guinea and Atlantic Ocean, in the sub region of West Africa $4^{\circ}$ north of the Equator. It has a land mass of $238,537 \mathrm{~km}^{2}$ and a population of approximately 27 million of which $59 \%$ is rural. Life expectancy at birth in 2013 was 62 years for males and 64 years for females [18]. The country is divided into ten administrative regions and 216 districts. Fifty-nine per cent of the Ghanaian workforce is in agriculture and almost everyone living in rural areas is involved in farming. Per capita total health expenditure as a percentage of GDP was $5.4 \%$ in 2013 [18]. About $24.2 \%$ of Ghanaians lived below the poverty line in 2013 [19]. In 2014, Ghana ranked 138 out of 187 countries and territories, with a Human Development Index value of 0.573 [20]. Fifty eight percent Ghanaians live less than 30 min of a public or private health facility, with better geographical within urban centres than rural settings [21]. The doctor-patient ratio in Ghana in 2011 was 1:10,034 [22] and almost $80 \%$ of Pharmacists are based in the two largest cities Accra and Kumasi [23]. About $60 \%$ of Ghanaians who report ill or injured consult a health practitioner while about one-third purchase medicines directly from retail drug outlets [21].

\section{Search strategy}

To identify relevant studies, we conducted a structured review of the literature followed by an analysis of the reported prevalence rates. The review was conducted in accordance with the PRISMA (Preferred Reporting Items for Systematic Reviews and Meta-Analyses) Statement [24]. A comprehensive search was conducted in PubMed, Science Direct, Google scholar, and Africa Journals Online (AJOL) databases. The key words used were Hepatitis B, Hepatitis B surface antigen, prevalence, Ghana, and similar terms such as HBV, HBsAg, were crossed. The main limits used were 'Humans' and 'English'.

\section{Inclusion and exclusion of studies}

We included only primary studies published in peerreviewed Journals between $1^{\text {st }}$ January 1995 and $4^{\text {th }}$ October 2015, which reported prevalence of HBV in a sample population in Ghana. Study quality was assessed using a 12-point scoring system based on the Downs and Black checklist as adopted in similar reviews $[25,26]$. These were: (objective of the study clearly described, study design clearly stated, participants representative of the population from which they were recruited, participants accrued during the same time period, modest sample size, management of missing data, age, gender and other characteristics explored/reported, e.g. were confounders reported, was detection method of HBV reported, were potential biases reported, was outcome clearly described?), the assessment also included other items known to be associated with study quality [26]. Studies were graded as high, medium or low based on quality 
scores. As globally agreed, laboratory diagnosis of hepatitis $B$ infection focuses on the detection of the hepatitis B surface antigen HBsAg [5, 27]. Studies were included only if they presented HBV prevalence based on HBsAg seropositivity. Each study was issued with a unique number for identification purposes and the following descriptive information collected; author details, year of publication, region of Ghana, type of study population, mean age of subjects, number of subjects involved (sample size), setting (rural or urban) and the HBV prevalence (as defined by HBsAg seropositivity). Study data were extracted by RO and Cross checked by AA. Where there were disagreements, these were resolved by consensus-based discussions.

\section{Data analysis}

The studies' results were analyzed by meta-analysis proportions which was performed with StatsDirect statistical software version (Version 3.0.0, StatsDirect Ltd, Cheshire UK) [28]. Individual study proportions were assessed at $95 \%$ confidence interval (CI) as well as the pooled effect. Test for heterogeneity was performed for all the proportions based on Cohran's Q and degree of inconsistency $\left(I^{2}\right)$ [29]. In all the summary or pooled analysis, random effect model was adopted over fixed effect model due to the presence of heterogeneity resulting from variations of effects from individual studies confirmed by $\mathrm{I}^{2}>0 \%$. For all computations, statistical significance was set at $p<0.05$. We conducted subanalyses for the periods within which studies were published (1995-2002, 2003-2009 and 2010-2015), among diverse population sub-groups (e.g. voluntary blood donors, family replacement donors and pregnant women \& parturients) and across the various regions of Ghana.

\section{Ethical approval}

This study did not require an ethical approval as it was based on information/data retrieved from published studies already available in the public domain.

\section{Results}

\section{Studies identification and retrieval}

Figure 1 outlines the schematic flow of the studies identification and inclusion processes. A total of 1,059 articles were identified by literature search. After the exclusion of duplicates and irrelevant studies based on titles and abstracts, 31 articles were retrieved for detailed full-text analysis. Out of the 30 studies, 28 met the inclusion criteria for addition to the review. Two (2) additional studies were retrieved from the reference screening bringing the total number of studies included in the review to $30[8,30-58]$. The 30 studies (Table 1) included in the review reported prevalence based on an overall population sample size of 105,435 across all the ten (10) regions of Ghana. The regional distribution of studies were, Ashanti (15), Greater Accra (5), Northern (2), Brong-Ahafo (2), Central (1), Eastern (1), Upper East

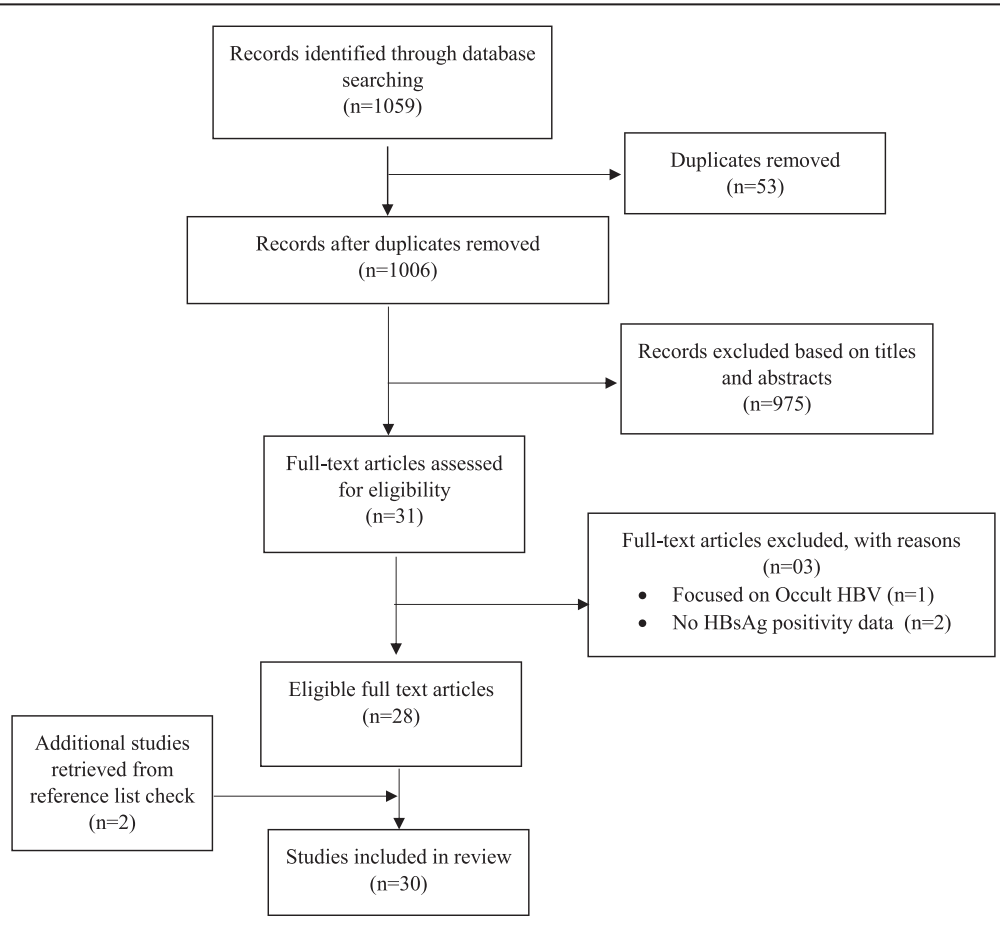

Fig. 1 Schematic flow diagram of studies' retrieval process 
Table 1 A summary of the descriptive characteristics of included studies

\begin{tabular}{|c|c|c|c|c|c|c|c|c|c|c|c|}
\hline Study No & Author Details & $\begin{array}{l}\text { Year of } \\
\text { Publication }\end{array}$ & Design & Region of study & Study population & Age group & Setting & $\begin{array}{l}\text { Sample } \\
\text { size(n) }\end{array}$ & Method & $\mathrm{HBsAg}+(\%)$ & $\begin{array}{l}\text { Quality } \\
\text { Grade }\end{array}$ \\
\hline 1 & Addai-Mensah et al. [30] & 2015 & Cross-sectional & Ashanti & Blood donors ${ }^{\mathrm{b}}$ & $17-60$ & Urban & 400 & Rapid test & $6.75 \%$ & Medium \\
\hline 2 & Adjei et al. [31] & 2006 & Cross-sectional & Eastern \& Greater Accra & Prison inmates \& Officers & $17-84$ & Urban & 363 & ELISA & $14.3 \%$ & High \\
\hline 3 & Adjei et al. [32] & 2008 & Cross-sectional & $\begin{array}{l}\text { National (Excludes Upper } \\
\text { East \& West) }\end{array}$ & Prison inmates \& Officers & $16-84$ & Urban & 1811 & ELISA & $22.1 \%$ & High \\
\hline 4 & Allain et al. [33] & 2003 & Cross-sectional & Ashanti & Blood donors \& Patients & $16-59$ & Urban & 383 & Mixed methods & $13.85 \%$ & High \\
\hline 5 & Allain et al. [34] & 2009 & Cross-Sectional & Ashanti & Blood donors & $>16$ years & Urban & 51100 & Rapid test & $11.3 \%$ & High \\
\hline 6 & Allain et al. [35] & 2010 & Cross-sectional & Ashanti & Blood donors & $31.0^{\mathrm{a}}$ & Urban & 11000 & Rapid test & $14.2 \%$ & High \\
\hline 7 & Amidu et al. [36] & 2010 & Cross-sectional & Upper East & Blood donors & $17-58$ & Urban & 4146 & Rapid test & $12.64 \%$ & Medium \\
\hline 8 & Amidu et a.l [37] & 2012 & Cross sectional & Ashanti & Community screenees & $15-38$ & Urban & 783 & Rapid test & $8.68 \%$ & High \\
\hline 9 & Antwi-Baffour et al. [38] & 2014 & Cross sectional & Greater Accra & Sickle cell patients & n.s & Urban & 202 & Rapid test & $3.50 \%$ & Low \\
\hline 10 & Apea-Kubi et al. [39] & 2006 & Cross-sectional & Greater Accra & $\begin{array}{l}\text { Pregnant \& non-pregnant } \\
\text { women }\end{array}$ & $29.6^{\mathrm{a}}$ & Urban & 517 & Rapid test & $16.8 \%$ & High \\
\hline 11 & Blankson et al. [8] & 2005 & Case-control & Greater Accra & $\begin{array}{l}\text { Cirrhotic \& non-cirrhotic } \\
\text { patients }\end{array}$ & $15-90$ & Urban & 350 & ELISA & $14.6 \%$ & High \\
\hline 12 & Candotti et al. [40] & 2007 & Cross-sectional & Ashanti & Pregnant women & n.s & Urban & 1368 & Rapid test & $16.0 \%$ & High \\
\hline 13 & Cho et al. [41] & 2012 & Cross-sectional & Eastern & Pregnant Women & n.s & Urban & 1500 & Rapid test & $10.6 \%$ & High \\
\hline 14 & Damale et al. [42] & 2005 & Cross-sectional & Greater Accra & $\begin{array}{l}\text { Parturients (pregnant } \\
\text { women) }\end{array}$ & $27.0^{\mathrm{a}}$ & Urban & 638 & n.s & $10.5 \%$ & Medium \\
\hline 15 & Dongdem et al. [43] & 2012 & Cross-sectional & Northern & Blood donors & $20-29$ years & Urban & 6321 & Rapid test & $11.5 \%$ & High \\
\hline 16 & Ephraim et al. [44] & 2014 & Cross-sectional & Central & Type 2 Diabetics & n.s & Urban & 110 & Rapid test & $5.50 \%$ & Medium \\
\hline 17 & Ephraim et al. [45] & 2015 & Cross-sectional & Ashanti & Pregnant women & 10-40 year & Urban & 168 & Rapid test & $16.0 \%$ & Medium \\
\hline 18 & Geretti et al. [46] & 2010 & Cross sectional & Ashanti & HIV patients & n.s & Urban & 838 & Mixed methods & $16.7 \%$ & High \\
\hline 19 & Kubio et al. [47] & 2012 & Report review & Northern & Blood donors & n.s & Rural & 853 & n.s & $7.50 \%$ & Low \\
\hline 20 & Matinson et al. [48] & 1996 & Cross-sectional & Ashanti & Children & $6-18$ & Rural & 803 & immunoassay & $15.8 \%$ & Medium \\
\hline 21 & Matinson et al. [49] & 1998 & Cross-sectional & Ashanti & Community screenees &.$>1$ & Rural & 1385 & immunoassay & $20.9 \%$ & Medium \\
\hline 22 & Mutocheluh et al. [50] & 2014 & Cross-sectional & Brong-Ahafo & Blood donors & $17-57$ & Urban & 164 & ELISA & $14.6 \%$ & High \\
\hline 23 & Nkrumah et al. [51] & 2011 & Cross-sectional & Ashanti & Blood donors & $26-35$ years & Rural & 2773 & Rapid test & $10.53 \%$ & Medium \\
\hline 24 & Nsiah et al. [52] & 2012 & Cross-Sectional & Ashanti & Sickle cell patients & $10-18$ & Urban & 330 & Immunoassay & $3.60 \%$ & Low \\
\hline 25 & Owiredu et al. [53] & 2012 & Cross-sectional & National (all regions) & Blood donors & n.s & Urban & 480 & Mixed methods & $8.13 \%$ & High \\
\hline 26 & Owusu-Ofori et al. [54] & 2005 & Cross-sectional & Ashanti & Blood donors & n.s & Urban & 9372 & Rapid test & $13.4 \%$ & High \\
\hline
\end{tabular}


Table 1 A summary of the descriptive characteristics of included studies (Continued)

\begin{tabular}{|c|c|c|c|c|c|c|c|c|c|c|c|}
\hline 27 & Rufai et al. [55] & 2014 & Cross-sectional & Ashanti & Blood donors & $16-59$ & Urban & 150 & Immunoassay & $13.3 \%$ & Medium \\
\hline 28 & Sagoe et al. [56] & 2012 & Cross-sectional & Greater Accra & HIV patients & $\geq 18$ years & Urban & 138 & ELISA & $13.0 \%$ & High \\
\hline 29 & Sarkodie et al. [57] & 2001 & Cross-sectional & Ashanti & Blood donors & $16-52$ & Urban & 3587 & Mixed methods & $15.3 \%$ & High \\
\hline 30 & Walana et al. [58] & 2014 & Cross-sectional & Brong-Ahafo & Blood donors & 20-49 years & Urban & 3402 & $\mathrm{ICT}$ & $9.60 \%$ & Medium \\
\hline
\end{tabular}

or replacement donors or both 
(1), two (2) inter-regional studies as well as one (1) national study involving all 10 regions. About $77 \%(23 / 30)$ of the studies were published in the years 2006-2015 compared to $23 \%$ (7/30) for the period 1995-2005. A significant proportion of the studies $(87 \%, 26 / 30)$ were conducted in urban settings. Also, about $60 \%(18 / 30)$ of the studies were published within the last 5 years (20102015) of the review period. Across studies, the sample sizes ranged from 110 to 51,100 . About $47 \%$ (14/30) of the studies were conducted in blood donors (voluntary and replacement family members). Only $20 \%(6 / 30)$ of studies were conducted exclusively in disease-specific patient groups (type-2 diabetes, HIV, Sickle cell anemia and cirrhosis). The overall quality grading identified 57, 33 and $10 \%$ of studies to be of high, moderate and low quality respectively.

\section{Overall national prevalence}

Of the 30 studies, the reported prevalence rates ranged from 3.5 to $22.1 \%$ (Table 1$)$. In $83 \%$ (25/30) of studies, the reported prevalence rates exceeded $8 \%$; the level used to define the endemicity level of an area as high. In $20 \%$ $(6 / 30)$ of studies, the reported prevalence was at least twice the $8 \%$. The pooled prevalence rate (Fig. 2) nationally across the 30 studies was $12.3 \%$ (95\% CI 11.3 to 13.4 ; $P<0.0001)$. The result of heterogeneity was also $94.6 \%$ (95\% CI 93.6 to $95.4 \%$ ) for the degree of inconsistency.

There was no evidence of publication bias with Egger's test having a $P=0.5273$, whereas Begg's test had a $P=00.8045$. This was depicted graphically by a funnel plot which showed a near symmetrical display of prevalence reported by various studies (Fig. 3).

\section{Blood donors}

Fourteen studies comprising a total population sample size of 93,990 presented HBV prevalence among blood donors (Voluntary and replacement blood donors). The HBV prevalence rate among these blood donors (BDs) as presented by these studies was within the range $6.75-15.3 \%$. For the 14 studies, $86 \%(12 / 14)$ reported prevalence rates above $8 \%$, the level used to define the endemicity level in an area as high [7]. The pooled prevalence rate (Fig. 4) across the 14 studies was $11.6 \%$ (95\% CI 10.6 to $12.6 ; P<0.0001$ ). The result of heterogeneity was also $93.2 \%$ (95\% CI 90.8-94.8\%) for the degree of inconsistency. Of the 14 studies on blood donors, 7

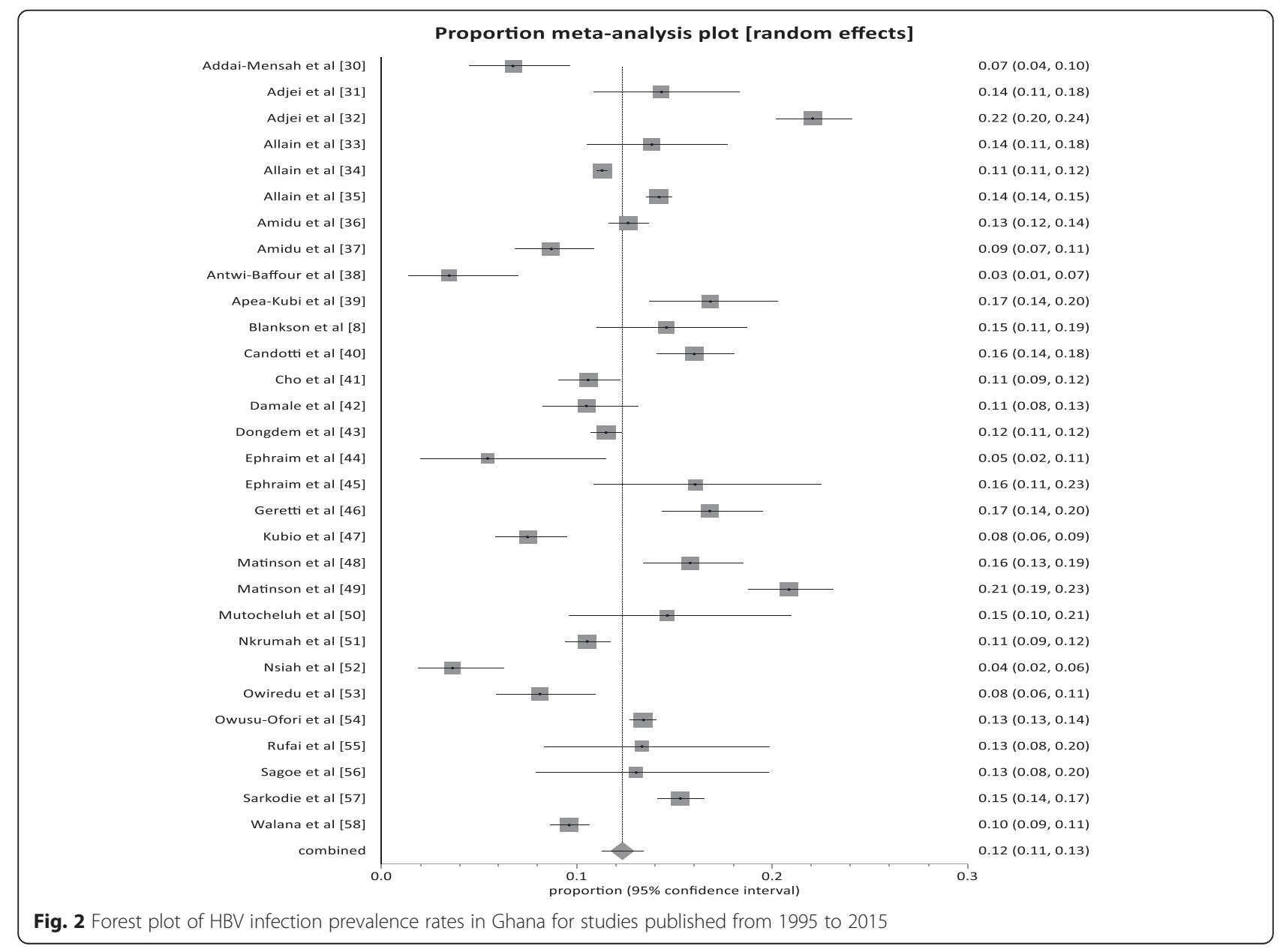




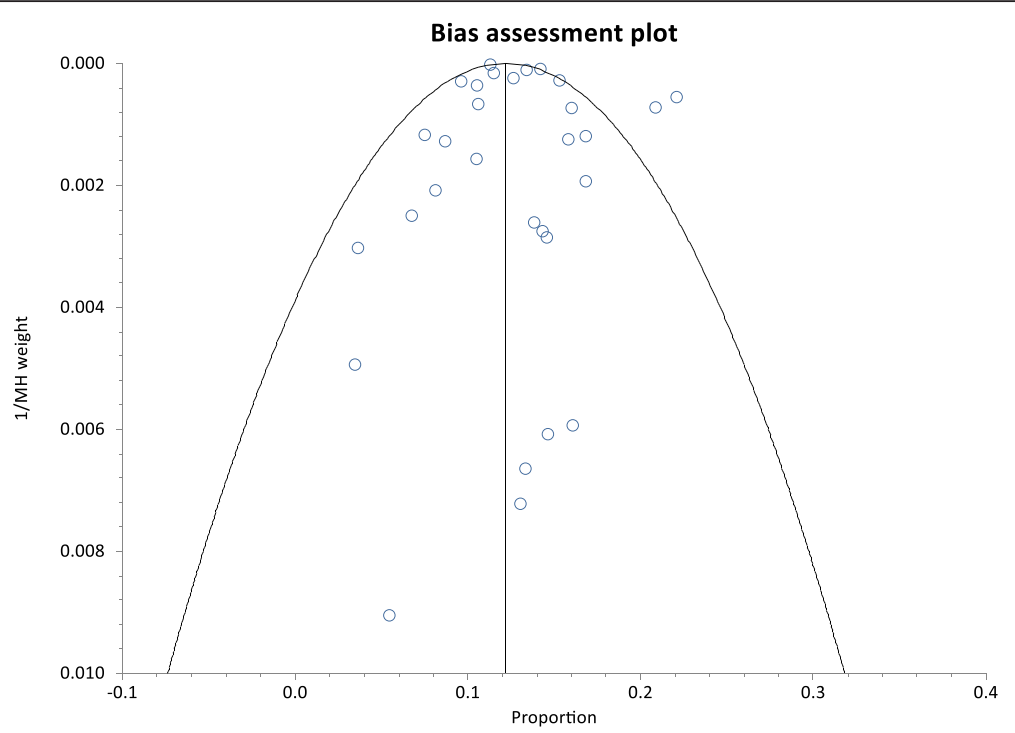

Fig. 3 Bias Assessment plot of studies reporting HBV prevalence in Ghana from 1995 to 2015

studies provided individual prevalence on voluntary blood donors (VBDs) and replacement donors (RBDs) based on a total sample size of 80,709 (VBDs $=44,213, \mathrm{RBDs}=$ $36,496)$. Among these studies, the pooled HBV prevalence among VBDs was $10.8 \%$ (95 \% 8.6 to 13.2; $P<0.0001)$ whereas among RBDs the prevalence rate was $12.7 \%(95 \% 11.1$ to $14.4 ; \quad P<0.0001)$. The difference $(1.90 \%$; $95 \% \mathrm{CI}=1.5$ to $2.4 \%)$ in $\mathrm{HBV}$ prevalence rate between the two donor types was statistically significant $(P<0.0001)$.

\section{Pregnant women \& parturients}

A total of 5 studies presented HBV prevalence rates among pregnant women and parturients. The combined

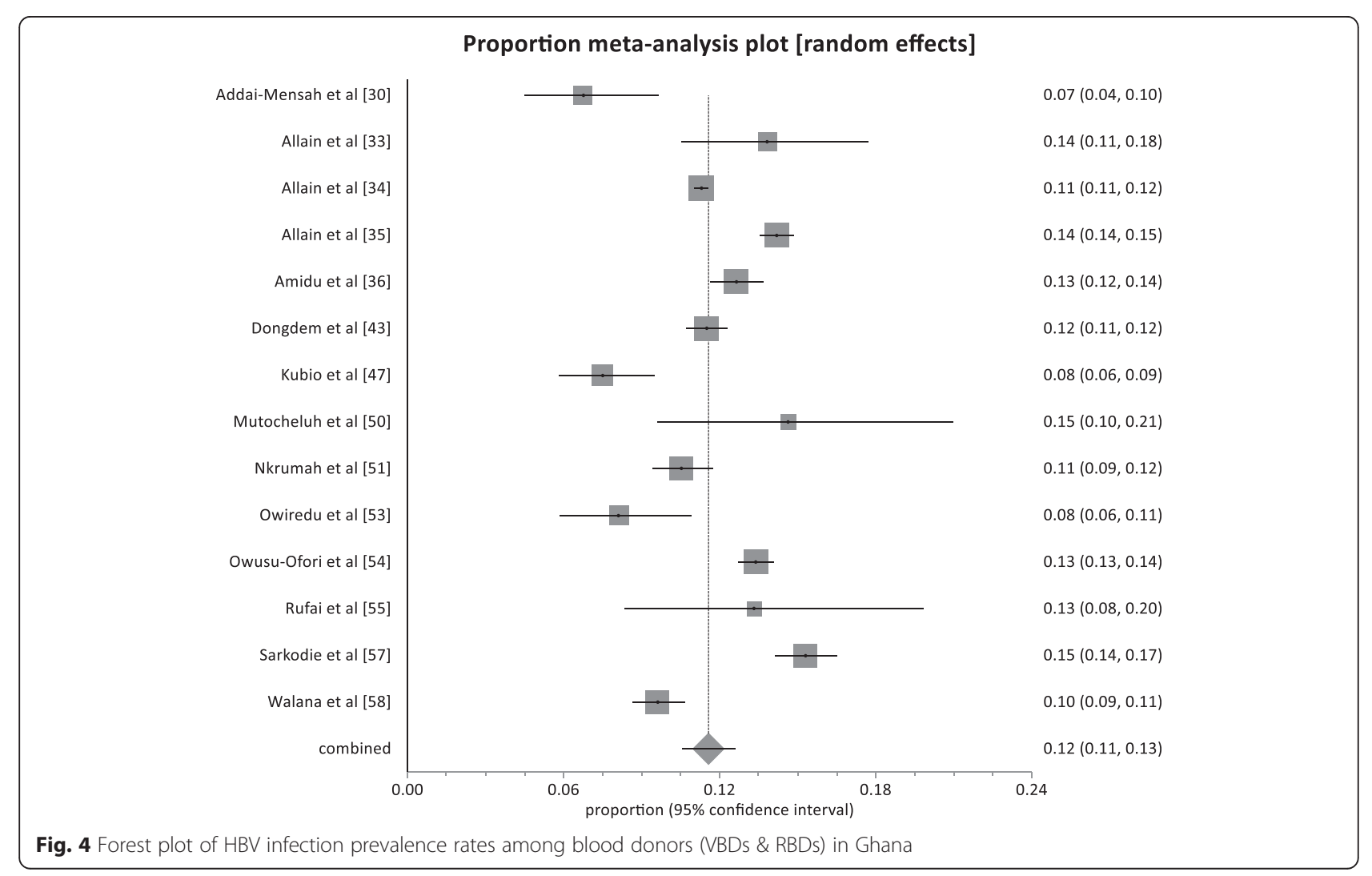


sample size across these studies was 3,968. The HBV prevalence rate in this group ranged from 10.5-16.0\%. The pooled prevalence rate (Fig. 5) across the 5 studies was $13.1 \%(95 \% \mathrm{CI}=10.4$ to $16.0 \% ; P<0.0001)$. The result of heterogeneity was also $82.9 \%(95 \% \mathrm{CI}=51.2$ to $90.9 \%$ ) for the degree of inconsistency. The difference in prevalence rate $(1.5 \%)$ between the pregnant \& parturient women population and the general population was not statistically significant $(P=0.1324)$.

\section{Prevalence related to socio-demographic characteristics}

Across studies included in the review, there was remarkable diversity in participants' age groups, although, majority of the studies were conducted in adult populations ( $>16$ years). The most prevalent age groups were not specified in 15 studies [31, 34, 40, $44-47,50-54,56,57]$. One study reported the highest prevalence of $\mathrm{HBV}$ infection in participants aged over 40 [33], while 9 studies reported in those aged 16-39 years. In 3 studies, the most prevalent HBV participants were aged $\geq 20$ years $[49,55$. 58]. In one (1) study the most prevalent HBV participant population was $<16$ years [49] where as in two (2) studies no observable difference was observed among different age groups $[41,48]$. The gender of the participants was not specified in 5 studies [46, 47, 52-54]. Five studies restricted to females [39-42, 45] and no study restricted to males only. Two studies $[48,51]$ documented no difference among male and female participants. Five (5) studies reported higher HBV prevalence among male participants in comparison with females [30, 36, 37, 49, 58] while opposite results were reported in two studies [32, 38]. One national study reported higher infection rate in females than males [32]. Two studies reported higher prevalence in married participants than unmarried persons $[42,50]$ whereas one study reported opposite results [32]. Two studies documented history of previous blood donation and one indicated higher infection in persons with previous history of blood donation [32] while the other study demonstrated no difference with blood donation non-recipients [50]. One study reported higher prevalence in homosexuals compared to heterosexuals [32].

\section{Prevalence comparison in rural and urban settings}

Four (4) studies were conducted within rural settings. These studies presented HBV based on a combined sample size of 5,814. The pooled prevalence rate (Fig. 6) across the studies conducted in rural settings was $13.3 \%$ (95\% CI 8.2 to $19.4 ; P<0.0001$ ). The result of heterogeneity was also $97.3 \%(95 \% \mathrm{CI}=95.9$ to $98.1 \%)$. Twenty-six (26) studies were conducted within urban settings. These studies presented HBV based on a combined sample size of 99,621 . The pooled prevalence rate (Fig. 7) across the studies conducted in urban settings was $12.2 \%$ (95\% CI $=11.1$ to $13.3 ; P<0.0001)$. The result of heterogeneity was also $94.1 \%(95 \% \mathrm{CI}=92.8$ to $95.0 \%)$. The difference (1.1\%; $95 \% \mathrm{CI}=0.21$ to $2.02 \%)$ in HBV prevalence rates across studies conducted in urban setting and those in rural settings was statistically significant $(P=0.0129)$.

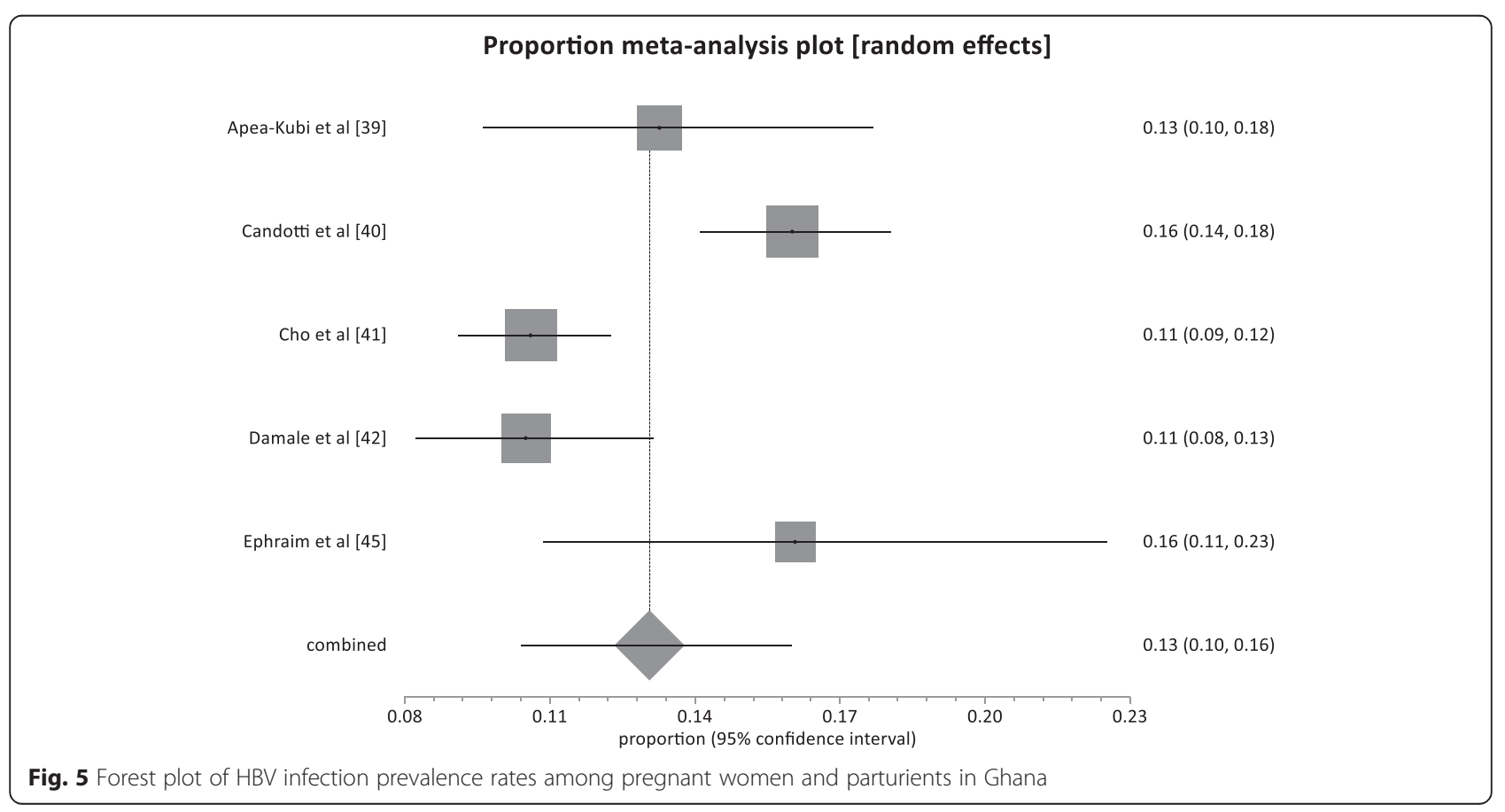




\section{Proportion meta-analysis plot [random effects]}

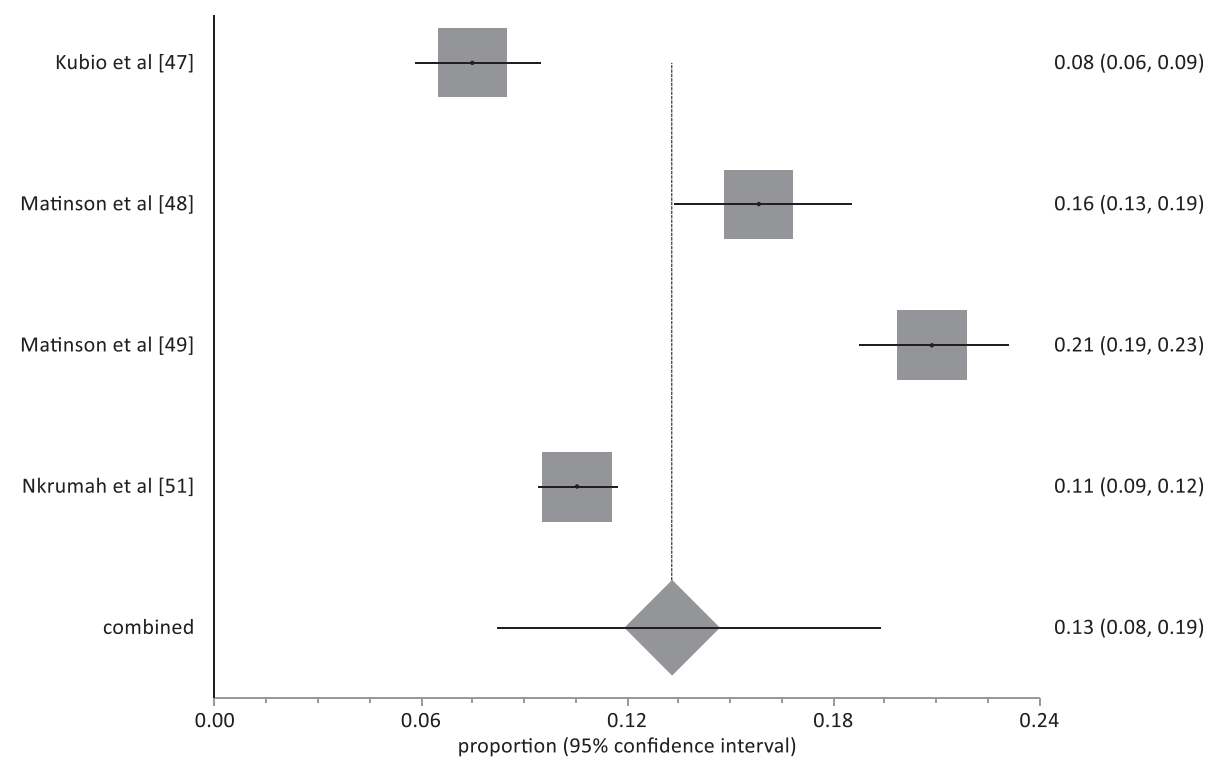

Fig. 6 Forest plot of HBV prevalence rates for studies conducted in rural settings in Ghana

\section{HBV prevalence by region}

Eight (8) studies presented HBV prevalence rates for the Greater Accra region, the second most populous region in Ghana. Among these studies, the HBV prevalence rates ranged from 0 to $16.8 \%$. The studies presented HBV prevalence based on a total population of 2,416. The pooled prevalence rate across the eight (8) studies was $10.6 \%$ (95\% CI $=7.3$ to $14.3 \% ; P<0.0001)$. The result of heterogeneity was also $86.5 \%$ for the degree of inconsistency. Five (5) studies presented HBV prevalence rates for the Brong-Ahafo region. Among these studies, the HBV prevalence rates ranged from 6.0 to $24.5 \%$. The studies presented HBV prevalence based on a total population of 3,828 . The pooled prevalence rate across the 4 studies was $13.7 \%$ (95 \% CI $=7.1$ to $22.1 \% ; P<0.0001)$. The result of heterogeneity was also $91.92 \%$ for the degree of inconsistency. Four (4) studies presented HBV prevalence rates for the Eastern region. Among these studies, the HBV prevalence rates ranged from 10 to $20 \%$. The studies presented HBV prevalence based on a total population of 1,766 . The pooled prevalence rate across the 4 studies was $13.6 \%$ (95 \% CI $=9.3$ to $18.5 \% ; P<0.0001$ ). The result of heterogeneity was also $64.3 \%$ for the degree of inconsistency. Three (3) Studies presented HBV prevalence rates for the central region, with prevalence rates ranging from 5.5 to $22.8 \%$ based on a sample size of 796. The pooled prevalence rate across the 3 studies was $11.5 \%$ (95\% CI $=3.9$ to $22.5 \%$; $P<0.0001$ ). The result of heterogeneity was also $93.28 \%$ for the degree of inconsistency. Prevalence data for the Northern region, the largest region in Ghana was retrieved from four (4) studies. Among these studies, the HBV prevalence rates ranged from 7.5 to $24.7 \%$. The studies presented HBV prevalence based on a total population of 7,488. The pooled prevalence rate across the 4 studies was $13.1 \%$ (95 \% CI $=8.6 \%$ to $19.8 ; P<0.0001)$. The result of heterogeneity was also $93.93 \%$ for the degree of inconsistency. For Ashanti region, the most populous region in Ghana, prevalence data were retrieved from seventeen (17) studies comprising a combined sample size of 84,694 . The HBV prevalence rate for this region ranged from 3.6 to $20.9 \%$. The pooled prevalence rate across the 17 studies was $13.1 \%$ (95 \% CI 11.7 to $14.5 ; P<0.0001$ ). The result of heterogeneity was also $94.9 \%$ for the degree of inconsistency. For the Volta, Upper East, Upper West and Western regions, it was not possible to generate aggregate data for the Volta, Upper east, upper west and western regions (Fig. 8).

\section{Prevalence by studies' publication period}

Studies' publication periods were grouped into 19952002, 2003-2009 and 2010-2015. Three (3), Nine (9) and eighteen (18) studies were published within these periods respectively. Among the studies published in the period 1995-2002, the HBV prevalence ranged from 15.3 to $20.9 \%$ based on a combined sample size of 5,775 . The pooled prevalence rate across the studies published within the period 1995-2002 was $17.3 \%$ (95\% CI 13.8 to $21.0 ; P<0.0001$ ). The result of heterogeneity was also $90.83 \%$. The nine (9) studies published 


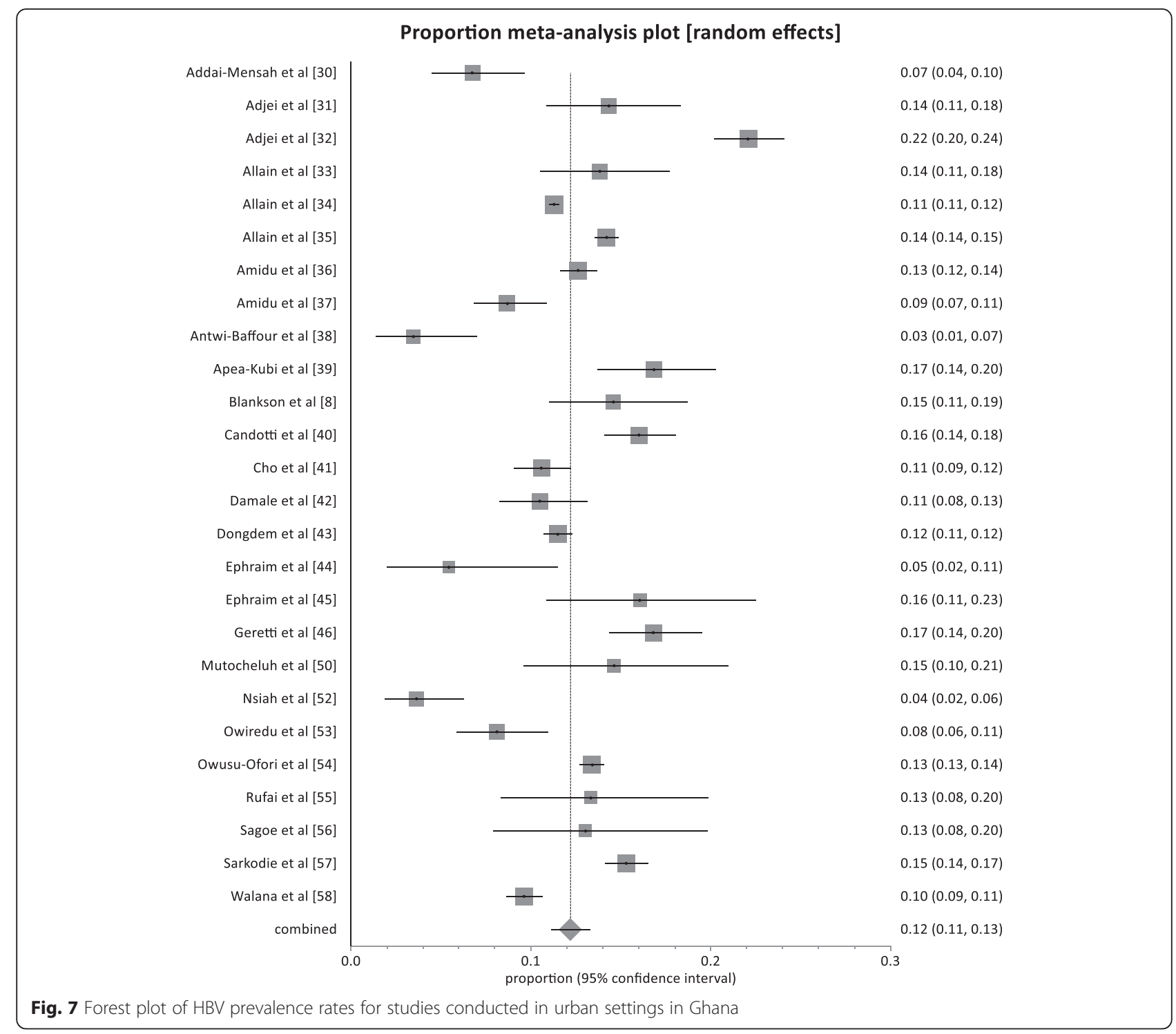

within the period 2003-2009 also presented HBV prevalence data based on a combined population size of 65,902 . The HBV prevalence rates for studies published within this period ranged from 10.5 to $22.1 \%$. The pooled prevalence rate across the studies published within the period 2003-2009 was $14.7 \%$ (95 \% CI 12.5 to $17.0 ; P<0.0001$ ). The result of heterogeneity was also $96.19 \%$. For the 18 studies published within the last 5 years (2010-2015) preceding the conduct of this review, the HBV prevalence ranged from 3.6 to $16.8 \%$ based on a combined sample size of 33,758 . The pooled prevalence rate (Fig. 6) across the studies published within the period $2010-2015$ was $10.2 \%$ (95 \% CI 8.9 to 11.6; $P<0.0001)$. The result of heterogeneity was also $91.78 \%$. Hence, the ascending order of prevalence according to studies' publication period was 2010-2015 < 2003-2009<1995-2002 (Fig. 9).

\section{Discussion}

Hepatitis B virus (HBV) infection is a major problem of public health in the world particularly in developing countries. Our review identified the prevalence of HBV in Ghana as detected by HBsAg seropositivity to be high at $12.3 \%$. Our result is comparable to the prevalence rate reported by Sweitzer et al's. review [3] albeit larger number of studies involved in our study. The results achieved is also in alignment with the categorization of Ghana as a high HBV endemic country (prevalence $\geq 8 \%)[8,15]$. The prevalence rate achieved significantly exceeds the reported global prevalence rate of $3.61 \%$ as well as the rate of 8 . $83 \%$ for the WHO Africa region [3]. In countries like the US, HBV prevalence rate has been estimated to be around $<0.27 \%$ [59]. In Iran and Kosovo current estimates put HBV prevalence at 2.14 and $4.2 \%$ 


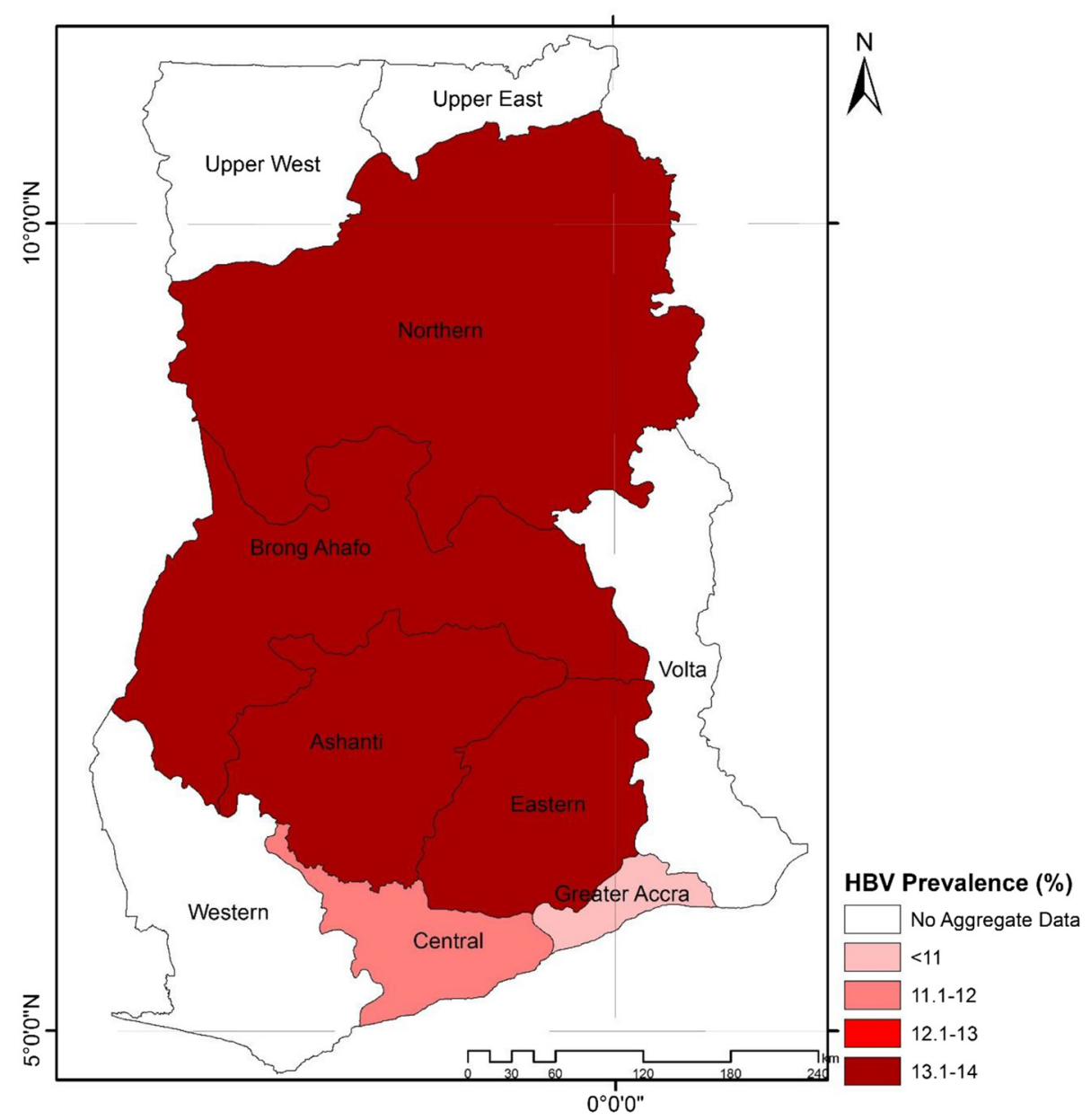

Fig. 8 Map of HBV prevalence across different regions in Ghana

respectively [60, 61]. Such comparative information further highlight the enormity of the HBV burden in Ghana.

Our study also raises serious concerns regarding the safety of blood supply in Ghana as nearly 1 in 9 blood donors may be infected with HBV with even higher proportions in replacement blood donors. Ghana has a national blood policy which requires the screening of all donated blood for HIV 1 and 2, HBV, Hepatitis C and Syphilis [62]. Our findings however highlight the need

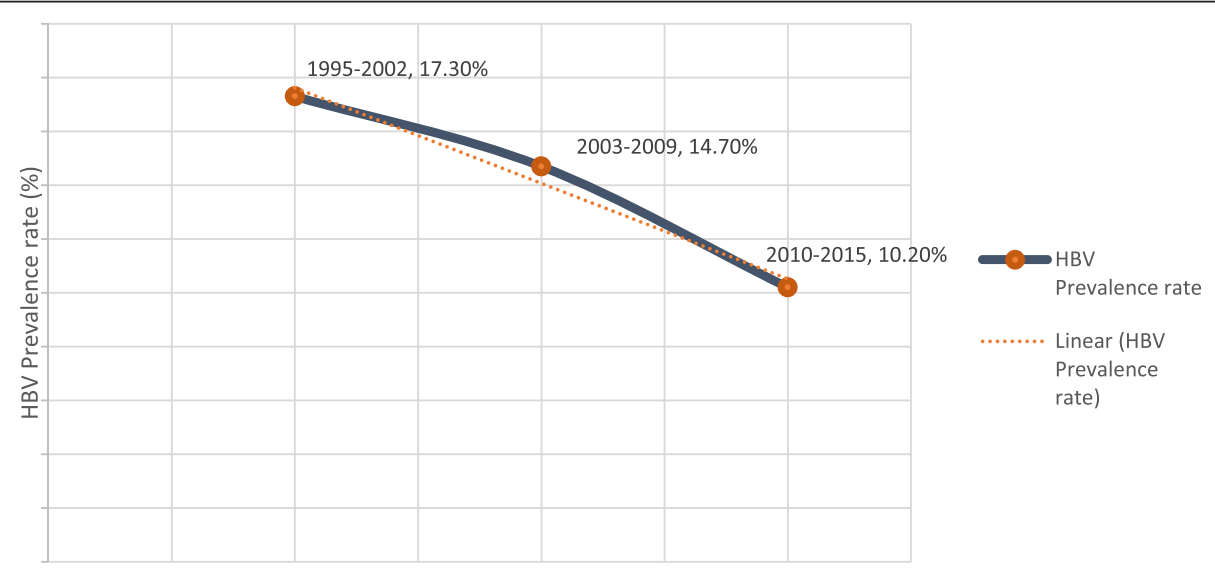

Fig. 9 A graph of HBV infection prevalence in Ghana according to studies' publication periods 
for stricter adherence to such policies as the risk of receiving contaminated blood, which in this is HBV remains high. Additionally, HBV infection among pregnant women also remains high $(\approx 1$ in 8$)$ and which justifies the establishment of a national HBV screening program for all pregnant women in antenatal clinics throughout Ghana. Additionally, a national policy to vaccinate all pregnant women who test negative for HBV should be adopted so as to reduce the risk of mother to child transmission within the population [45].

A number of factors may account for the observed high HBV prevalence in Ghana. This includes lack of adequate information and understanding among Ghanaians of the transmission dynamics of the virus. For instance, in an assessment of 200 barbershops within the Kumasi metropolis, only $7 \%$ knew the route of transmission of HBV [63]. Akumiah and Sarfo further point out that, the barber community in Ghana paid more attention to the decoration (e.g., availability of television, air conditioning, sound system etc.) other than the risk factors associated with their profession in the transmission of diseases such as HBV [64]. Although, the 3 main transmission routes of HBV in Ghana are transfusion of infected blood, unprotected sex and mother to child transmission, and most Ghanaians with chronic hepatitis B were infected at birth or in childhood, HBV has often been framed as a sexually transmitted infection in many communities and even among health workers [13]. Stigmatization arising from such misconceptions has many times prevented patients from finding their way to proper care and subsequently reducing their infectivity rates.

There are three (3) key components to controlling hepatitis B. These include treating infected persons, interrupting the spread of the infection transmission and reducing the mortality associated with advanced hepatic disease and $\mathrm{HCC}$ [65]. A vaccine against hepatitis B has been available since 1982. The vaccine is safe and $95 \%$ effective in preventing infection and the development of chronic disease and HCC due hepatitis B [5]. For instance, in Senegal, vaccinations have reduced infection rates among children from 18.7 to $2.2 \%$, whereas in Gambia, it has led to a reduction in infection rate from $10 \%$ to less than $1 \%$ [66]. Ghana introduced Hepatitis $B$ vaccination of babies as part of the Expanded Programme of Immunization (EPI) in 2002 [13]. Babies from 6 weeks onwards receive the pentavalent vaccine (diphtheria, polio, tetanus, hepatitis B, influenza type B). The coverage of EPI is good in all regions of the country and among the highest in Sub-Saharan Africa [67]. The introduction of the HBV vaccine in 2002 may have by inference contributed to the lowering of prevalence rates as studies published in the post vaccine introduction periods 2003-2015 recorded lower HBV prevalence rates than the pre-vaccine introduction period (19952002).

On the other hand, although, Ghana's National Health Insurance Scheme (NHIS) introduced in 2003, aims to improve access to health services by eliminating financial barriers (particularly out-of pocket payments), hepatitis B screening and vaccination in Ghana outside EPI are still not covered under the scheme. Screenings are only covered and prescribed at hospitals for patients suspected to be reactive to hepatitis B and/or C. Hepatitis B immunoglobulin $\mathrm{G}$ and hepatitis $\mathrm{B}$ monovalent vaccine for babies born to hepatitis $\mathrm{B}$ reactive mothers are also not covered by the NHIS [68]. These may have all hampered effective control of the disease over the last couple of years.

Epidemiological studies have demonstrated that rapid urbanization, overpopulated cities and poor socioeconomic conditions such as lack of access to clean water and sanitation are implicated in the burden of HBV [69]. The World Bank notes that over the last 2 decades, there has been a steady increase in the proportion of Ghanaians with access to portable water with current rates exceeding $88 \%$ [70]. Nevertheless, less than $15 \%$ of Ghanaians have access to proper sanitation [71]. Martinson et al. [48], has demonstrated that the improvement of socioeconomic conditions may lead to a decreasing exposure to viral hepatitis such as HBV in Ghana. Hence, the apparent reported lower prevalence rate within the period 2003-2015, may have been due to the combined effect of vaccine introduction and improvement in some socioeconomic conditions. Better socioeconomic improvement and vaccination coverage in urban areas compared to rural areas may underline the difference in HBV prevalence rates difference between these two settings. However, it is unclear the extent to which factors such as vaccination and socioeconomic conditions have played in the slight regional variations in HBV prevalence across the country.

Although, there exist significant gaps in the evidence documenting the burden of HBV on individuals, the healthcare system and the country as whole, the cost associated with HBV in Ghana can be enormous because of the high morbidity and mortality associated with endstage liver disease, cirrhosis and HCC. Blankson et al., identified that over 2 in 5 cirrhotic patients in Ghana had chronic HBV [8]. The cost of oral treatment for HBV in Ghana is about GHC 300-400 (USD100-150) a month or same weekly to take an injection for 48 weeks as a way of managing the condition [72]. This cost is enormous and one that majority of Ghanaians cannot afford. Even if this was to be publicly funded, the impact on health expenditure would be significant. Moreover, as identified from the studies, the most prevalent 
population was 16-39 years covering some of the most productive age groups. Thus the economic impact of HBV in Ghana through loss of life and absenteeism from work cannot be underestimated.

Addressing Ghana's high HBV prevalence should remain a key national priority and one that needs strategic public health interventions. In 2014, the World Health Assembly adopted the second WHO resolution on viral hepatitis (WHA67.6), providing guidance to governments on how to prioritize actions to tackle all forms of viral hepatitis in a coordinated manner [73]. Subsequently, the recently released WHO guidelines on the management of chronic hepatitis B highlights the importance of adopting a simplified public health approach to controlling the virus [74]. The key highlights of this guideline includes developing publicly-funded screening and treatment programmes and providing universal access to hepatitis B prevention, care and treatment. Scaling up this programme in Ghana will have two main benefits. Firstly, it will expand access to the general population. And secondly, it will strengthen the diagnostic services and laboratory infrastructure to support care. In line with this, Hepatitis B vaccination should be covered by the NHIS, preferably for every citizen. If this is not achievable owing to resource limitations, it should be made available at least to all family members/close contacts of persons with hepatitis B in efforts to reduce horizontal transmission of the disease.

Effectively tackling HBV burden calls for a stronger political will and a wider social involvement. The aim will be to solidify the inclusion of HBV prevention in the overall national health agenda and salvage the needed resources to execute the necessary interventions. Lemoine et al. makes interesting reference to lessons learnt from the HIV/AIDS epidemic and advocates that the same energy and mobilization must be applied to fighting viral hepatitis such as HBV [1]. Within the HIV/ AIDS domain, pressure from patient advocacy groups and civil societies for instance "pushed" policy makers and drug manufacturers to lower the cost of ARTs to the current level of around USD100 per person per year from about $\$ 10,000$ per patient per year in the early 2000s [1]. This has subsequently had tremendous impact on the number of individuals receiving ART. Also integrating viral hepatitis programmes into the existing national health programmes around Tuberculosis (TB) or HIV may allow shared synergies in terms of the programme's success and limit its cost $[1,65]$.

This study raises a number of key issues regarding HBV research in Ghana. Firstly, while there seems to be a positive trend of increased research in this area characterized by $60 \%$ of papers being published in the last 5 years, there are widespread regional variations in the level of research. About $75 \%$ of studies were conducted in two regions (Ashanti \& Greater Accra) and in four regions it was not possible to derive aggregate data due to limited number of studies. Moreover, studies were concentrated in adult populations giving little information about HBV prevalence in children which is a better predictor of the level of maternofaetal transmission [48]. Likewise most studies provided no information regarding the relationship between prevalence and sociodemographic characteristics such as religion, income, and type of occupation all of which are recognized predictors of HBV prevalence [75]. Further research in these areas would be needed to fully understand the dynamics of HBV burden in Ghana.

\section{Limitations}

The accuracy of detection of active HBV infection depends on a number of factors such as the screening method employed [25]. The distinction of active from past infection usually requires the adoption of other methods including the identification of HBV IgM and HBV markers. Advanced methods such as DNA testing may be able to detect the presence of hepatitis even before the appearance of antibodies [25, 76]. Since, our review was conducted over a 20 -year period, the studies involved may have used different generations of screening kits and there may be a variation in the sensitivity and specificity which could impact on the difference in prevalence rates between the different study publication periods. The majority of the studies analyzed used convenient samples and the risk profile may not be fully representative of the Ghanaian population. Moreover, of the 105,435 population size involved in the 30 studies, a significant proportion $(89.1 \% n=93,990)$, were among blood donors who are populations with specific characteristics. In Ghana, women and children are not frequent donators of blood as compared to young and middleaged men. Hence, the HBV prevalence, may be more representative of a young and middle-aged male population. Moreover, with the regional imbalance in the number of studies, the overall prevalence may not be entirely representative of a true national prevalence. Regardless of the above limitations, our review provides a useful estimate of the prevalence of HBV in Ghana as it is similar to prevalence rates quoted by some experts and also comparable to results from other countries within the sub-region $[3,16,17]$. Also, with the majority of studies published recently, the overall prevalence is likely to reflect current situation.

\section{Conclusion}

In conclusion, there is a high burden of chronic HBV infection among Ghanaians. This is a preventable disease and indeed one that can be eradicated by vaccination. Addressing the challenges of HBV infection in Ghana will 
require multi-level approaches that includes populationwide educational interventions and a strengthening of the Ghanaian health system. There is urgent need for the government of Ghana and its international partners to prioritize HBV control as done successfully for conditions such as HIV, Malaria and TB. This is necessary to prevent a potential future explosion of HBV in Ghana.

\section{Availability of data and materials}

We declare that the data supporting the conclusions of this article are fully described within the article.

\begin{abstract}
Abbreviations
AIDS: Acquired immune deficiency syndrome; ART: Antiretroviral therapy; HBV: Hepatitis B virus; HBsAg: Hepatitis B surface antigen;

HCC: Hepatocellular carcinoma; HIV: Human immunodeficiency virus; NHIS: National health insurance scheme; PRISMA: Preferred reporting items for systematic reviews and meta-analyses; RBD: Replacement blood donor; SSA: Sub-Saharan Africa; TB: Tuberculosis; VBD: Voluntary blood donor; WHO: World Health Organization; ELISA: Enzyme-linked immunosorbent assay; ICT: Immunochromatography.
\end{abstract}

\section{Competing interests}

The authors declare that they have no competing interests.

\section{Authors' contribution}

$\mathrm{RO}$ conceptualized the study and drafted an outline. Both RO and AA were involved in the database search, studies retrieval, data extraction and analysis. All authors contributed equally to preparing the Manuscript and approve of the content.

\section{Acknowledgement}

The authors are grateful to Mr. George Ashiagbor of Kwame Nkrumah University of Science and Technology (KNUST) for assistance in developing the chloropleth map.

\section{Source of funding}

None.

Received: 29 October 2015 Accepted: 15 March 2016

Published online: 18 March 2016

\section{References}

1. Lemoine M, Eholié S, Lacombe K. Reducing the neglected burden of viral hepatitis in Africa: strategies for a global approach. J Hepatol. 2015;62(2):469-76.

2. Lok AS. Chronic hepatitis B. New Engl J Med. 2002;346(22):1682-3.

3. Schweitzer A, HorJ J, Mikolajczyk RT, Krause G, Ott JJ. Estimations of worldwide prevalence of chronic hepatitis B virus infection: a systematic review of data published between 1965 and 2013. Lancet. 2015;386(No. 10003):1546-55.

4. Goldstein ST. A mathematical model to estimate to estimate global hepatitis B disease burden and vaccination impact. Int J Epidemiol. 2005; 34(6):1329-39.

5. World Health Organization. Hepatitis B. http://www.who.int/mediacentre/ factsheets/fs204/en/(2015). Accessed 01 Oct 2015.

6. Ott JJ, Stevens GA, Groeger J, Wiersma ST. Global epidemiology of hepatitis $B$ virus infection: new estimates of age-specific HBsAg seroprevalence and endemicity. Vaccine. 2012;30(12):2212-9.

7. Kiire CF. The epidemiology and prophylaxis of hepatitis B in sub-Saharan Africa: a view from tropical and subtropical Africa. Gut. 1996;37 Suppl 2:S5-S12.

8. Blankson A, Wiredu EK, Adjei A, Tettey Y. Seroprevalence of hepatitis B and C viruses in cirrhosis of the liver in Accra, Ghana. Ghana Med J. 2005;39(4):132-7.

9. Howell J, Ladep NG, Lemoine M, Thursz MR, Taylor-Robinson SD. Hepatitis B in Sub-Saharan Africa. South Sudan Med J. 2014;7(3):59-61.
10. Parkin DM, Bray F, Ferlay J, Pisani P. Global cancer statistics. 2002. CA Cancer J Clin. 2005;55(2):74-108.

11. Parkin DM, Sitas F, Chirenje M, Stein L, Abratt R, Wabinga H. Part I: Cancer in Indigenous Africans-burden, distribution, and trends. Lancet Oncol. 2008;9(7):683-92.

12. Kirk GD, Lesi OA, Mendy M, Akano AO, Sam O, Goedert JJ, et al. The Gambia Liver Cancer Study: Infection with hepatitis B and C and the risk of hepatocellular carcinoma in West Africa. Hepatology. 2004;39(1):211-9.

13. Owusu-Ansah T. Viral Hepatitis in Ghana: The Role of the Government http:// www.ghanaweb.com/GhanaHomePage/NewsArchive/Viral-Hepatitis-In-GhanaThe-Role-Of-The-Government-222118. (2014). Accessed 01 Oct 2015.

14. Mkandawire P, Richmond C, Dixon J, Luginaah IN, Tobias J. Hepatitis B in Ghana's upper west region: a hidden epidemic in need of national policy attention. Health Place. 2013;23:89-96.

15. Averhoff F. Hepatitis B. http://wwwnc.cdc.gov/travel/yellowbook/2016/ infectious-diseases-related-to-travel/hepatitis-b (2015). Accessed 02 Oct 2015.

16. GhanaWeb. Ghana Rated High Risk for Hepatitis B and C. http://www. ghanaweb.com/GhanaHomePage/health/Ghana-rated-high-risk-forHepatitis-B-C-280781 (2013). Accessed 30 September 2015.

17. Teye J. Ghana risks losing productive youth to Hepatitis-Medical Professor. http://www.myjoyonline.com/lifestyle/2015/September-15th/ghana-riskslosing-productive-youth-to-hepatitis-medical-professor.php (2015). Accessed 30 November 2015.

18. World Health Organization. Ghana. http://www.who.int/countries/gha/en/ (2015). Accessed 30 November 2015.

19. Central Intelligence Agency. The World Factbook. https://www.cia.gov/ library/publications/the-world-factbook/fields/2046.html (2014). Accessed 30 November 2015

20. UNDP. Ghana Launches the 2014 Human Development Report. http://www. gh.undp.org/content/ghana/en/home/presscenter/articles/2014/08/13/ ghana-launches-the-2014-human-development-report.html (2014). Accessed 01 Oct 2015.

21. Bosu WK. Epidemic of Hypertension in Ghana: a systematic review. BMC Public Health. 2010:10:418

22. Ghana News Agency. Access to Pharmaceutical Services in favour of Urban Areas. http://www.ghananewsagency.org/health/access-to-pharmaceuticalservices-in-favour-of-urban-areas-mr-nyoagbe-15819 (2010). Accessed 02 Oct 2015.

23. Alhassan RK, Nicole Spieker N, Ostenberg PV, Ogink A, Nketiah-Amponsah E, Tobias F, Rinke de Wit TF. Association between health worker motivation and healthcare quality efforts in Ghana. Hum Resour Health. 2013;11:37.

24. Moher D, Liberati A, Tetzlaff J, Altman DG. Preferred reporting items for systematic reviews and meta-analyses: the PRISMA statement. Ann Intern Med. 2009:151(4):264-9. w64.

25. Musa B, Bussell S, Borodo MM, Samaila AA, Femi OL. Prevalence of hepatitis $B$ virus infection in Nigeria, 2000-2013: a systematic review and metaanalysis. Niger J Clin Pract. 2015;18:163-72.

26. Downs SH, Black N. The feasibility of creating a checklist for the assessment of the methodological quality both of randomized and non-randomized studies of health care interventions. J Epidemiol Community Health. 1998;52(6):377-84

27. Krajden $M, M c N a b b G$, Petric $M$. The laboratory diagnosis of hepatitis $B$ virus. Can J Infect Dis Med Microbiol. 2005:16(2):65-72.

28. StatsDirect. Proportion Meta-analysis http://www.statsdirect.com/help/ default.htm\#meta_analysis/proportion.htm. Accessed 04 February 2016.

29. Higgins JPT, Thompson SG, Deeks JJ, Altman DG. Measuring inconsistency in meta-analyses. Br Med J. 2003;327(7414):557-60.

30. Addai-Mensah O, Bashiru PA, Dogbe EE. Safety of family replacement donors vs. voluntary non-remunerated donors in Komfo Anokye Teaching Hospital, Ghana: a comparative study. J Med Biomed Sci. 2015;4(1):11-6.

31. Adjei AA, Armah HB, Gbagbo F, Ampofo WK, Quaye IK, Hesse IF, Mensah G. Prevalence of human immunodeficiency virus, hepatitis $B$ virus, hepatitis $C$ virus and syphilis among prison inmates and officers at Nsawam and Accra, Ghana. J Med Microbiol. 2006:55(Pt 5):593-7.

32. Adjei AA, Armah HB, Gbagbo F, Ampofo WK, Boamah I, Adu-Gyamfi C, Asare I, Hesse IF, Mensah G. Correlates of HIV, HBV, HCV and syphilis infections among prison inmates and officers in Ghana: a national multicenter study. BMC Infect Dis. 2008;8:33.

33. Allain JP, Candotti D, Soldan K, Sarkodie F, Phelps B, Giachetti C, Shyamala V, et al. The risk of hepatitis B virus infection by transfusion in Kumasi, Ghana. Blood. 2003;101(6):2419-25. 
34. Allain JP, Opare-Sem O, Sarkodie F, Rahman R, Owusu-Ofori S. Deferred donor care in a regional hospital blood center in Ghana. Transfusion. 2009;49(4):669-75.

35. Allain JP, Sarkodie F, Asenso-Mensah K, Owusu-Ofori S. Relative safety of first-time volunteer and replacement donors in West Africa. Transfusion. 2010;50(2):340-3.

36. Amidu N, Owiredu WB, Addai-Mensah O, Alhassan A, Quaye L, Batong B. Seroprevalence and risk factors for human immunodeficiency virus, hepatitis $B$ and $C$ Vi-ruses infections among blood donors at the Bolgatanga Regional Hospital in Bolgatanga, Ghana. J Ghana Sci Assoc. 2010;12:1.

37. Amidu N, Alhassan A, Obirikorang C, Feglo P, Majeed SF, Timmy-Donkoh E, Afful D. Sero-prevalence of hepatitis B surface ( $\mathrm{HBsAg})$ antigen in three densely populated communities in Kumasi, Ghana. J Med Biomed Sci. 2012;1 (2):59-65.

38. Antwi-Baffour SS, Adarkwah-Yiadom K, Kyeremeh R, Adjei DN, Abdulai MS, Ayeh-Kumi PF. Incidence of hepatitis B surface antigen among sickle cell disease patients receiving transfusion therapy. Int J Biomed Sci Engineering. 2014:2(1):7-10.

39. Apea-Kubi KA, Yamaguchi S, Sakyi B. Ofori-Adjei D.HTLV-1 and other viral sexually transmitted infections in antenatal and gynaecological patients in Ghana. West Afr J Med. 2006;25(1):17-21.

40. Candotti D, Danso K, Allain JP. Maternofetal transmission of hepatitis B virus genotype E in Ghana, West Africa. J Gen Virol. 2007:88(Pt 10):2686-95.

41. Cho Y, Bonsu G, Akoto-Ampaw A, Nkrumah-Mills G, Nimo JJ, Park JK, Ki M. The prevalence and risk factors for hepatitis B surface Ag positivity in pregnant women in eastern region of Ghana. Gut Liver. 2012;6(2):235-40.

42. Damale NK, Lassey AT, Bekoe V. Hepatitis B virus seroprevalence among parturients in Accra, Ghana. Int J Gynecol Obstet. 2005;90:240-1.

43. Dongdem JT, Kampo S, Soyiri IN, Asebga PN, Ziem JB, Sagoe K. Prevalence of hepatitis $B$ virus infection among blood donors at the Tamale Teaching Hospital, Ghana (2009). BMC Res Notes. 2012;5:115.

44. Ephraim RK, Nsiah P, Osakunor DN, Adoba P, Sakyi SA, Anto EO. Seroprevalence of hepatitis $B$ and $C$ viral infections among type 2 diabetics: a cross-sectional study in the Cape Coast Metropolis. Ann Med Health Sci Res. 2014:4(5):719-22.

45. Ephraim R, Donkor I, Sakyi SA, Ampong J, Agbodjakey H. Seroprevalence and risk factors of hepatitis $B$ and hepatitis $C$ infections among pregnant women in the Asante Akim North Municipality of the Ashanti region, Ghana; a cross sectional study. Afr Health Sci. 2015;15(3):709-13.

46. Geretti AM, Patel M, Sarfo FS, Chadwick D, Verheyen J, Fraune M, Garcia A, Phillips RO. Detection of highly prevalent hepatitis B virus coinfection among HIV-seropositive persons in Ghana. J Clin Microbiol. 2010:48(9):3223-30.

47. Kubio C, Tierney G, Quaye T, Nabilsi JW, Ziemah C, Zagbeeb M, Shaw, Murphy WG. Blood transfusion practice in a rural hospital in Northern Ghana, Damongo, West Gonja District. Transfus Pract. 2012;52:2161-6.

48. Martinson FE, Weigle KA, Mushahwar IK, Weber DJ, Royce R, Lemon SM. Seroepidemiological survey of hepatitis $B$ and $C$ virus infections in Ghanaian children. J Med Virol. 1996;48(3):278-83.

49. Martinson FE, Weigle KA, Royce RA, Weber DJ, Suchindran CM, Lemon SM. Risk factors for horizontal transmission of hepatitis B virus in a rural district in Ghana. Am J Epidemiol. 1998;147(5):478-87.

50. Mutocheluh M, Owusu M, Kwofie TB, Akadigo T, Appau E, Narkwa PW. Risk factors associated with hepatitis B exposure and the reliability of five rapid kits commonly used for screening blood donors in Ghana. BMC Res Notes. 2014;7:873.

51. Nkrumah B, Owusu M, Frempong HO, Averu P. Hepatitis B and C viral infections among blood donors from Rural Ghana. Ghana Med J. 2011:45(3):97-100

52. Nsiah K. The prevalence of seropositivity to hepatitis B surface antigen and the corresponding hemato-biochemical features in sickle cell patients in Ghana. J Haematol Malig. 2012;2(1):13-8.

53. Owiredu WK, Osei-Yeboah J, Amidu N, Laing EF. Residual risk of transmission of hepatitis B virus through blood transfusion in Ghana: evaluation of the performance of rapid immunochromatographic assay with enzyme linked immunosorbent assay. J Med Biomed Sci. 2012;1(2):17-28.

54. Owusu-Ofori S, Temple J, Sarkodie F, Anokwa M, Candotti D, Allain JP. Predonation screening of blood donors with rapid tests: implementation and efficacy of a novel approach to blood safety in resource-poor settings. Transfusion. 2005;45(2):133-40.

55. Rufai T, Mutocheluh M, Kwarteng K, Dogbe E. The prevalence of hepatitis B virus E antigen among Ghanaian blood donors. Pan Afr Med J. 2014;17:53.
56. Sagoe KW, Agyei AA, Ziga F, Lartey M, Adiku TK, Seshi M, Arens MQ, Mingle $J A$. Prevalence and impact of hepatitis $B$ and $C$ virus co-infections in antiretroviral treatment naïve patients with HIV infection at a major treatment center in Ghana. J Med Virol. 2012;84(1):6-10.

57. Sarkodie F, Adarkwa M, Adu-Sarkodie Y, Candotti D, Acheampong JW. Screening for viral markers in volunteer and replacement blood donors in West Africa. Vox Sang. 2001;80:142-7.

58. Walana W, Hokey P, Ahiaba S. Sero-prevalence of hepatitis B virus infection among blood donors: a retrospective study in the Kintampo Municipal hospital, Ghana. Open J Med Microbiol. 2014;4:64-9.

59. Wasley A, Kruszon-Moran D, Kuhnert W, Simard EP, Finelli L, McQuillan G, Bell B. The prevalence of hepatitis B virus infection in the United States in the Era of vaccination. J Infect Dis. 2010;202(2):192-201.

60. Alavian SM, Hajarizadeh B, Ahmadzad-Asl M, Kabir A, Bagheri-Lankarani K. Hepatitis B virus infection in Iran: a systematic review. Hepatitis Monthly. 2008;8(4):281-94.

61. Fejza H, Telaku S. Prevalence of HBV and HCV among blood donors in Kosovo. Virol J. 2009;6:21.

62. World Health Organization. Ghana National blood Policy. http://www.who int/bloodsafety/transfusion_services/GhanaNationalBloodPolicy2006.pdf Accessed 10 January 2016.

63. Mutocheluh M, Kwarteng K. Knowledge and occupational hazards of barbers in the transmission of hepatitis B and C was low in Kumasi, Ghana. Pan Afr Med J. 2015;20:260

64. Akumiah PO, Sarfo LA. Knowledge and practices of certified barbers about hepatitis B and C transmission in Kumasi, Ghana. Appl Res J. 2015:1(2):27-35.

65. Lesi O. Hepatitis B in Africa: the challenges in controlling the scourge. http://theconversation.com/hepatitis-b-in-africa-the-challenges-incontrolling-the-scourge-43818 (2015). Accessed 02 Oct 2015

66. Vildósola $\mathrm{GH}$. Hepatitis $\mathrm{B}$, vaccination impact on acute disease, chronic carriers and hepatocarcinoma incidence. Rev Gastroenterol Peru. 2000;20(4):414-21.

67. Menaca A, Tagbor H, Adjei R, Bart-Plange C, Collymore Y, Ba-Nguz A, Mertes K, Bingham A. Factors likely to affect community acceptance of a malaria vaccine in two Districts of Ghana: a qualitative study. PLoS One. 2014;9(10):e109707.

68. World Hepatitis Alliance. Ghana Survey highlights. http://webcache googleusercontent.com/search?q=cache:So4LDh_banUJ:global-report. worldhepatitisalliance.org/en/download/civil-society-download. html\%3Ffile\%3Dfiles/global_report/download/CS\%2520countries/Ghana.pdf $+\& c d=1 \& h|=e n \& c t=c| n k \& g \mid=g h$ (2013). Accessed 01 Oct 2015.

69. World Health Organization. Water Related Diseases. http://www.who.int/ water_sanitation_health/diseases/hepatitis/en/(2015). Accessed 02 Oct 2015

70. The World Bank Group. Improved water source (\% of population with access). http://data.worldbank.org/indicator/SH.H2O.SAFE.ZS (2015). Accessed 03 Oct 2015.

71. UNICEF. Ghana-WASH in Communities. http://www.unicef.org/ghana/wes. html (2013). Accessed 02 Oct 2015

72. Myjoyonline. Direct policy interventions towards treatment of Hepatitis B Pharmacist http://lifestyle.myjoyonline.com/pages/health/201108/70392.php (2011). Accessed 01 October 2015.

73. World Health Organization. World Health Assembly approves resolution on hepatitis and mechanism to coordinate non-communicable disease response. (2014) http://www.who.int/mediacentre/news/releases/2014/ WHA-20140522/en/Accessed 03 Oct 2015.

74. World Health Organization. Guidelines for the prevention, care and treatment of persons with chronic hepatitis B infection. http://www.who.int/ hiv/pub/hepatitis/hepatitis-b-guidelines/en/(2015). Accessed 02 Oct 2015.

75. Yohanes T, Zerdo Z, Chufamo N. "Seroprevalence and Predictors of Hepatitis B Virus Infection among Pregnant Women Attending Routine Antenatal Care in Arba Minch Hospital, South Ethiopia," Hepatitis Research and Treatment. vol. 2016, Article ID 9290163, 7 pages, 2016. doi:10.1155/2016/ 9290163

76. Kuhns MC, Busch MP. New strategies for blood donor screening for hepatitis B virus: nucleic acid testing versus immunoassay methods. Mol Diagn Ther. 2006;10:77-91. 